\title{
Inking in Surgical Pathology: Does the Method Matter? A Procedural Analysis of a Spectrum of Colours
}

\author{
Divya PURSNANI, Swati ARORA, Katyayani PALUR, Ambica C, Balasaheb Ramling YELIKAR \\ B.L.D.E.U's Shri B.M Patil Medical College, Department of Pathology, VIJAYAPURA, INDIA
}

\begin{abstract}
Objective: Proper identification of surgical margins along with margin status holds utmost importance in histopathology. Inking margins is one way. India ink has long been used but it can ink only one margin. On other hand acrylic colours, available in variety of colours can be used for inking multiple margins along with many more advantages. The present study was undertaken to analyse acrylic colours and Indian ink for inking surgical margins via three different methods for optimum results.

Material and Method: Thirteen acrylic colours along with India ink were evaluated via three different methods on radical specimens of breast and colon after preliminary requisites of grossing were completed. In Method 1, coloured inks were applied to an overnight formalin fixed specimen and representative sections were taken. In Method 2, the specimen was inked and kept for overnight fixation. The specimen was sampled following day. In Method 3, the specimen was inked and kept for overnight fixation. The following day, it was re-coloured with the same colours as of the previous day and subsequently sections were taken. Coloured inks were assessed on different parameters for their performance as surgical ink and given scores.
\end{abstract}

Results: Acrylic shades \#04, \#22, \#06, \#01, \#02 and India ink had very good to excellent score on microscopy in all three methods. Shades \#64, $\# 18$, \#09, \#23 had poor microscopic visibility in all three methods. Shade \#09 showed loss of colour and the shade \#23 showed penetration into deeper tissues on microscopy. Results were best with Method 3 followed by Method 1 and 2, respectively.

Conclusion: Acrylic colours have more advantages compared to India ink. Method 3 is recommended for inking. Few acrylic shades meet the criteria of surgical inks in all three methods.

Key Words: Inks, Acrylic colours, India ink, Surgical pathology

\section{INTRODUCTION}

Histopathological assessment of radical or wide excision specimens requires proper orientation of the specimen along with identification of all surgical margins (1-8). Several methods have been utilised for margin assessment like the marking of surgical margins with sutures and clips or applying India ink $(1,2)$. India ink has long been used in the field of surgical pathology $(1,2,5,7,9,10)$. However, when multiple margins are to be assessed, there has been a lack of use of varied coloured inks $(1,2)$. The use of an assortment of ink colours is useful in the following ways: 1) For margin status, 2) For orientation of a specimen, 3) For the benefit of post-grossing three-dimensional reconstruction, 4) To reduce identification error when multiple sampling is required from the same tissue (e.g. prostate needle biopsies) or when obtaining similar specimens from different patients (e.g. biopsies) $(1,2,10,11)$.

(Turk Patoloji Derg 2016, 32:112-118)

Received : 13.12.2015 Accepted : 08.02.2016
Indeed, many times the critical decision of whether the margin is positive for tumour cells depends entirely on the presence or absence of ink (4).

Though tissue marking dyes (TMD) are available in the market, they are expensive and not readily available $(2,3,7,8)$. Acrylic colours are easily available in numerous colours, and are affordable, non-toxic, non-flammable and stable $(1,3,6,7,10)$ (Figure 1A-E). However, not all acrylic colours withstand tissue processing and fulfill the criteria of being used as surgical ink; plus though the inking has to be done before grossing, whether application of ink after overnight fixation is better or inking followed by fixation and grossing is preferable is to be sought.

The objective in this study was to analyze different commercially available acrylic colours and India ink for inking surgical margins; and also to analyze these coloured inks by three different methods for optimum results and convenience of use.

Correspondence: Balasaheb Ramling YELIKAR

Department of Pathology, B.L.D.E.U's Shri B.M Patil Medical College,

VIJAYAPURA, INDIA

E-mail: yelikar61@gmail.com Phone: +919448139588 

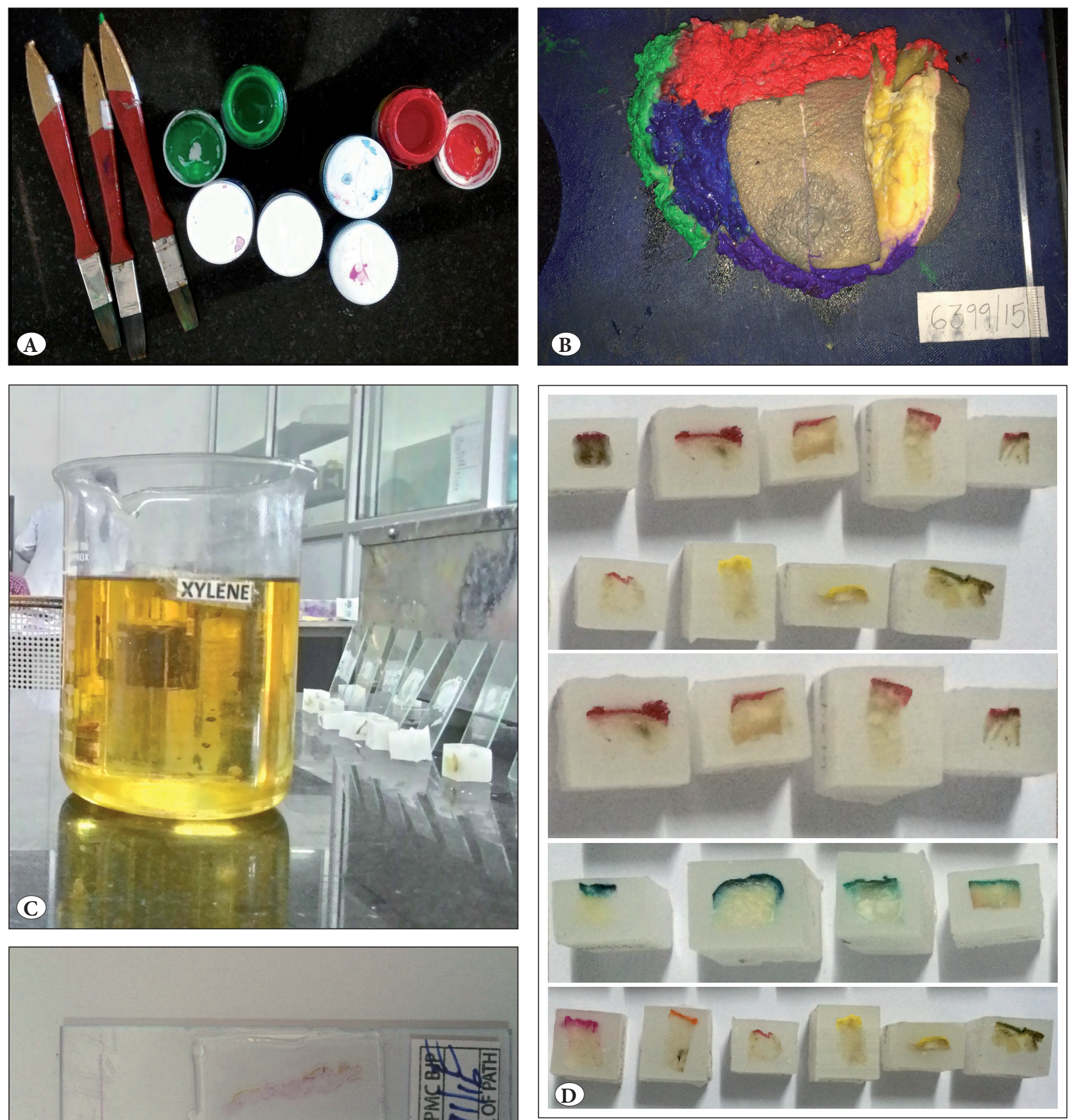

Figure 1: A) Acrylic colours and paint brushes. B) Inking of gross specimen by acrylic colours. C) Contamination of processing fluid by acrylic yellow colour. D) Visibility of acrylic colours on blocks.

(E) E) Visibility of acrylic colours on naked eye examination of slide. 


\section{MATERIAL and METHODS}

This was a cross-sectional comparative study. Radical surgical specimens of breast and colon were included in the study. After the preliminary requisites of gross specimens were completed, the specimens were taken for grossing. Thirteen Fevicryl ${ }^{\circ}$ acrylic hobby idea colours (Table I) along with India ink were used in the study. Inking was done using half inch paint brushes. After each application, brushes were thoroughly washed with water before the next application. The colour inks and India ink were analysed for their effectiveness as surgical inks via three different methods. India ink was also analysed by the following three methods which were used for analysis of coloured inks.

Method 1: An overnight formalin-fixed specimen was patted dry with a paper towel and all surgical margins were inked with different colours. The inks were allowed to air dry and representative sections from the coloured margins were taken.

Method 2: The specimen was patted dry with a paper towel and all surgical margins were inked with different colours. After air drying, the specimen was kept for overnight fixation. Following day, representative sections from the coloured margins were taken.

Method 3: The specimen was patted dry with a paper towel and all surgical margins were inked with different colours. After air drying, the specimen was kept for overnight fixation. Following day, the specimen was re-coloured with the same colours as on the previous day and representative sections from the coloured margins were taken.

Sections were cut at $4 \mu \mathrm{m}$ thickness and stained with haematoxylin and eosin (H\&E).

The coloured inks were assessed on the following parameters:

1) Ease of application,

2) Drying time of ink,

3) Contamination of other tissues and processing fluids,

4) Visibility on paraffin blocks,

5) Visibility on slide,

6) Visibility on microscopy,

7) Penetration into deeper tissue and interference with nuclear and cytoplasmic morphology.

Visibility on microscopy of the coloured inks was scored between 1 and 4 by individual observations. Score 1 was excellent, 2 was very good, 3 was good and 4 was poor. For each colour in the three respective methods an average score was calculated and the results were tabulated (Table I).

Statistical analysis in the study was by mean and standard deviation.

Table I: Analysis of Acrylic Colours and India Ink via Methods 1, 2 and 3 on microscopy

\begin{tabular}{|c|c|c|c|c|}
\hline S. No & Colour & Method 1 & Method 2 & Method 3 \\
\hline 1 & Deep brilliant purple (No. 64) & 4 & 4 & 3.66 \\
\hline 2 & Dark green (No. 6) & 1.66 & 1.33 & 1 \\
\hline 3 & Mauve (No. 15) & 2 & 2.66 & 2.33 \\
\hline 4 & Black (No. 2) & 1 & 2.33 & 1.66 \\
\hline 5 & Pink (No. 18) & 3.66 & 3.66 & 3.66 \\
\hline 6 & Burnt sienna (No. 1) & 1 & 2 & 1.33 \\
\hline 7 & Orange (No. 17) & 2 & 2.33 & 1 \\
\hline 8 & Golden yellow (No. 9) & 4 & 4 & 4 \\
\hline 9 & Turquoise blue (No. 22) & 1 & 1.66 & 1 \\
\hline 10 & Ultramarine blue (No. 23) & 3.66 & 3.66 & 3.33 \\
\hline 11 & Prussian blue (No. 19) & 1.33 & 1.66 & 2.66 \\
\hline 12 & Light green (No. 12) & 2.33 & 1.33 & 1.33 \\
\hline 13 & Crimson red (No. 4) & 1.33 & 1 & 1 \\
\hline 14 & India ink & 1 & 1.66 & 1.33 \\
\hline 15 & Overall Mean \pm SD of all colours for each of the 3 different Methods & $2.2 \pm 1.2$ & $2.4 \pm 1.1$ & $2.1 \pm 1.2$ \\
\hline
\end{tabular}

No.: Acrylic colour shade number. 


\section{RESULTS}

In method 1, three acrylic colours (black, burnt sienna, turquoise blue) and India ink gave excellent results on microscopic examination. In method 2, crimson red (acrylic colour) gave excellent result on microscopic examination. In method 3, four acrylic colours (dark green, orange, turquoise blue, crimson red) gave excellent results on microscopic examination. Some acrylic colours had a shade lighter on gross specimen during method 2, e. g orange and burnt sienna. These colours gave better performance with method 3. The performance of other colours on microscopic examination is enlisted in Table I. Mean \pm SD of all colours for method 1 was $2.2 \pm 1.2$, for method 2 was $2.4 \pm 1.1$ and for method 3 was $2.1 \pm 1$.2. Least value of mean was observed for method 3 followed by method 1 and 2, respectively. Thus, method 3 showed best results followed by method 1 and 2 , respectively.

Analysis of coloured inks on the above mentioned parameters is interpreted (Table II) as follows:

Visibility on paraffin block: All the acrylic colours and India ink had good visibility on the paraffin blocks.

Visibility on naked eye examination of slides: Out of 1260 slides, 29 slides did not show visibility on the slide.

Visibility on microscopy: Out of 1260 sections, 24 sections showed near total loss of colour on microscopic examination. 120 sections had interrupted staining on microscopy (turquoise blue, ultramarine blue, Prussian blue, light green).
Penetration into deeper tissues and interference with nuclear and cytoplasmic details: Out of 1260 slides, 117 slides (ultramarine blue) showed penetration of the colour into the underlying tissue interfering with the nuclear and cytoplasmic details.

Drying time: Time required for drying of acrylic colours was significantly lower than that of India ink.

Ease of application: Radical specimens were painted by 13 different commercially available acrylic colours and India ink with different brushes. All the colours applied had equal ease of application.

Contamination of other tissues and processing fluids: Processing fluids and other solutions showed contamination by yellow colour.

\section{DISCUSSION}

Presence or absence of tumour cells in the surgical margins holds important therapeutic and prognostic implications. Till date, morphological assessment of margin status is considered the gold standard $(1,2,5,6)$. Also, orientation or laterality of the excised specimen is desirable for both post-grossing specimen examination and microscopic identification of resected margins $(1,2,7)$. Inking the margins is more reliable than sectioning techniques and suture markers, for identification of surgical margins before and after tissue processing $(2,10)$. India ink is the traditional marking ink in the field of surgical pathology $(1,2)$. Other marking techniques include painting with Alcian blue, plain gelatine, gelatine with added colours, TMD, erythrocytes and surface coating with starch $(3,6,7)$.

Table II: Analysis of Acrylic Colours and India Ink on different parameters

\begin{tabular}{|l|l|c|c|c|}
\hline S. No & Parameters & Ink & Sample size & Result \\
\hline \multirow{2}{*}{1} & \multirow{2}{*}{ Ease of application } & Acrylic & 1260 & $100 \%$ \\
\cline { 3 - 5 } & & India ink & 1260 & $100 \%$ \\
\hline \multirow{2}{*}{2} & \multirow{2}{*}{3 Drying time of ink } & Acrylic & 1260 & $1.28(1.26-1.33 \mathrm{~min})$ \\
\cline { 3 - 5 } & \multirow{2}{*}{ Contamination of other tissues and processing fluids } & India ink & 1260 & $2.44(2.28-3.00 \mathrm{~min})$ \\
\cline { 3 - 5 } & & Acrylic & 1260 & $33(2.6 \%)$ \\
\hline \multirow{2}{*}{4} & \multirow{2}{*}{ Visibility on paraffin blocks } & Acrylic & 1260 & None \\
\cline { 3 - 5 } & & India ink & 1260 & $100 \%$ \\
\hline \multirow{2}{*}{5} & \multirow{2}{*}{ Visibility on naked eye examination of slides } & Acrylic & 1260 & $1260 \%$ \\
\hline \multirow{2}{*}{6} & \multirow{2}{*}{ Visibility on microscopy } & India ink & 1260 & $100 \%$ \\
\hline \multirow{2}{*}{7} & Penetration into deeper tissues and interference with \\
\cline { 3 - 5 } & nuclear and cytoplasmic morphology & Acrylic & 1260 & $1236(98 \%)$ \\
\cline { 3 - 5 } & Acrylic & 1260 & $100 \%$ \\
\hline
\end{tabular}


Currently, margins are marked by TMD, gelatine, Alcian blue, inorganic artist's pigment suspended in acetone, India ink and acrylic colours (3-5,7-10). There are some known disadvantages such as inorganic pigments tend to be radio dense and mimic or obscure micro calcification on sliced specimen mammogram; gelatine requires reheating and maintaining its liquid state is laborious and time consuming; TMDs are expensive, hazardous, have a longer drying time and can cause false positive results with immunohistochemical stains $(2,7,8)$.

First used in the $20^{\text {th }}$ century, acrylic paints are coloured particulate pigments suspended in acrylic polymer solutions as a thick emulsion. They are increasingly popular, cost-effective, non-hazardous, easy to apply, dry quickly, insoluble in water and solvent once dry thus being long lasting $(1-3,6,10)$ (Table III). As they are available in varied colours, multiple margins can be marked $(2,10)$. It allows multiple usages as acrylic paint brushes and other equipment can be washed with soap and water. Acrylic colours can be painted in layers and as they are not transparent previous colour is not seen through (2). India ink on the other hand is a colloidal suspension of inert carbon black used since fourth century B. C under the name of "Mashi" in India (1).

All shades of acrylic colours do not fulfil the criteria to be used as surgical ink. Few shades that fix on fresh and formalin fixed tissue, withstand tissue processing and routine $\mathrm{H} \& \mathrm{E}$ staining and are visible on both block and microscopic examination, without contaminating processing fluids and not obscuring nuclear and cytoplasmic morphological details suffice the criteria of surgical ink (1). Acrylic colours have an added advantage that they do not interfere with immunohistochemical staining $(1,6,10)$. They are easily available in stationary shops and can be bought as single units at nominal prices $(1,2)$.

In our study acrylic shades numbered 04 (crimson), 22 (turquoise blue), 06 (dark green), 01 (burnt sienna) and 02 (black) had very good to excellent score on microscopic examination in all three methods. (Figure 2A-F) Shade 17 (orange) had excellent visibility when used by method 3 whereas it had good to very good visibility through methods 1 and 2 . Shade 15 (mauve) had very good visibility in methods 1 and 3 but good in method 2. Shades 64 (deep brilliant purple), 18 (pink), 09 (golden yellow), 23 (ultramarine blue) had poor microscopic visibility in all methods. Golden yellow in every method and in all slides showed loss of colour and presented as black colour with foci of yellow colour. (Figure 2A-F) Shade 12 (light green) and 19 (Prussian blue) had good visibility on microscopy. The results were in accordance with the study done by Tampi and Chiam et al. The authors also stated that acrylic colours were easily visible both macroscopically and microscopically $(1,7)$.

We observed that the outcome, out of the three methods was best by method 3 followed by 1 and 2 respectively. method 2 had least performance because the colours painted on the surgical margins were a shade lighter after overnight formalin fixation. Method 3 gave best results as the specimens were re-coloured after overnight formalin fixation thus compensating for any loss of colour. The outcome of method 1 was mediocre as the specimens were directly sent for tissue processing without overnight formalin fixation.

A similar observation was made with regards to visibility of colours on the paraffin blocks and on naked eye examination of the slides. Method 2 had slightly lighter colour on blocks compared to blocks made by methods 1 and 3, the latter again having the best colour visibility. Few colours were discernible only on microscopic examination of the section though not identified specifically externally on the paraffin blocks or slides. This was especially seen for mauve colour (shade 15). Also in a few cases scanner (x40) identification of mauve colour was difficult and confirmation was obtained only on low (x100) and high power $(\mathrm{x} 400)$. A similar observation was made by Williams et al. in their study (6).

Table III: Comparison of Acrylic Colours and India Ink

\begin{tabular}{|l|l|}
\hline Acrylic colours & India ink \\
\hline Available in multiple colours & Available as black colour commonly \\
\hline More economical & Comparatively expensive \\
\hline Takes less time to dry & Takes longer time to dry \\
\hline Non-toxic, non-flammable & Toxic \\
\hline Multiple surfaces can be marked in different colours in a given specimen & Only one surface can be marked in a given specimen \\
\hline Few shades are unsuitable for use as a surgical ink & Suitable and used as a surgical ink \\
\hline
\end{tabular}



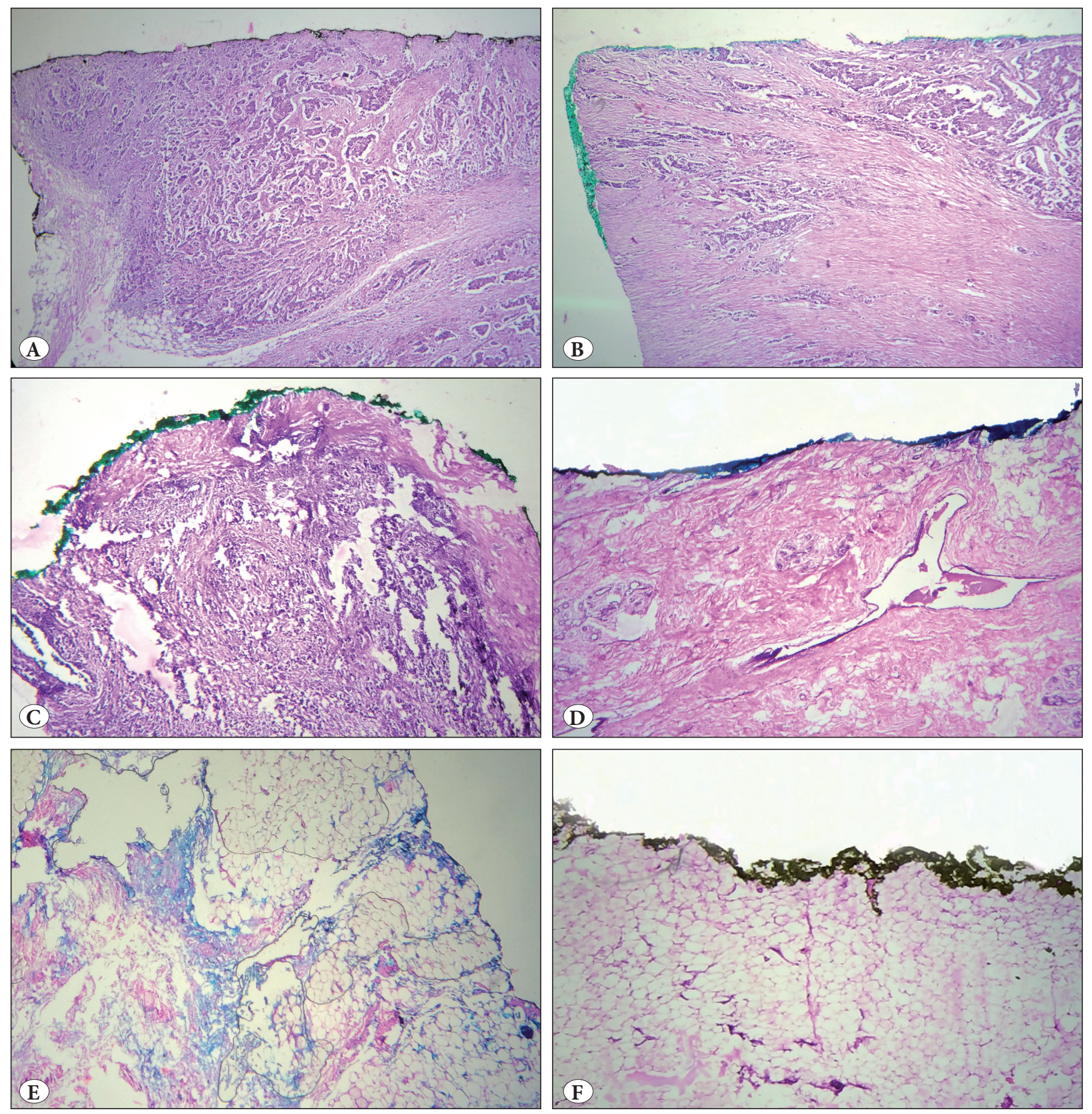

Figure 2: Micrographs showing excellent visibility of acrylic colours. A) Black. B) Light green. C) Dark green. D) Turquoise blue on microscopy (H\&E; x100). E) Micrograph showing penetration of acrylic colour ultramarine blue into deeper tissue (H\&E; x100). F) Micrograph showing loss of colour by acrylic yellow colour (H\&E; x100).

Shade 23 (ultramarine blue) showed penetration into deeper tissues leading to obscuration of cellular and nuclear morphology (Figure 2A-F) All acrylic colours showed equal ease of application. In a similar study done by Sarode et al.; acrylic colours had faster drying time compared to
India ink, thus making them better suited for routine use (2). Tissue marking dyes also take a longer time to dry and thus are cumbersome to use (7). It was observed in our study that yellow colour caused contamination of tissue processing solutions contrary to India ink in the study done by Sarode et al. (2) (Figure 1A-E). 
Method 3 overall had highest degree of precision in both block and microscopic findings followed by method 1 and 2 respectively. A slight difference between method 1 and 3 was observed. Keeping this in mind, it is best if we use method 3 but if convenience and less time for grossing are desirable, even method 1 is more than sufficient and gives approximately same results. However, consideration should be kept in mind that the colours which gave similar results for both methods 1 and 3 should be used (e. g. shades numbers $01,02,04,06,22)$. There are some colours where significant difference was observed between methods 1 and 3 and with such colours it is preferable to follow method 3 for better outcome.

Every laboratory should have a protocol for inking margins and should standardize different colours for different margins (10). Some studies report that few marking inks mimic microcalcification on specimen radiography of breast lumpectomies and should be avoided, where microcalcification is required to be identified after excision by prior testing radio-opacity of ink $(1,11)$.

A wide range of acrylic colours is available in market, but trial and error is needed before they can be used in surgical pathology. Acrylic black colour (No. 02) gave excellent performance on all study parameters and therefore can be used instead of India ink which is comparatively expensive, takes longer time to dry and is toxic (2). Acrylic colours require less time to dry compared to tissue marking dyes and are therefore preferable in a busy surgical laboratory (9).

The present study had certain limitations. The study included limited set of acrylic colours and only one manufacturer colours were analysed. Also the assessment in the study was on the subjective interpretation of the authors. Analyses of multiple colours from multiple manufactures need to be tried. Image analysis has been used in some studies. Though it provides quantitative interpretation, it does not include subjective observation of human colour perception and its use is not practical for routine surgical pathology practice.

In conclusion, acrylic colours are easily available, more affordable and easy to use compared to India ink with an added advantage of multiple colours for different margins. Inking by method 3 is recommended. Acrylic shades of 04 (crimson), 22 (turquoise blue), 06 (dark green), 01 (burnt sienna) and 02 (black) had very good to excellent visibility on microscopic examination in all the three methods.

\section{ACKNOWLEDGEMENT}

The authors express their gratitude to the staff of Department of Pathology for their constant encouragement and guidance. We are thankful to Mr. Mohd Shannawaz for his help in statistical analysis of the study. We are grateful to Mrs Jessy Joseph, Mr. N B Mathad and Mrs. V P Pawar for their co-operation and technical assistance. The authors would also like to thank Dr. Abhey Chawla, Dr. Lynda Rodrigues and Dr. Jyotsna W for their help during the research project.

\section{CONFLICT OF INTEREST}

Authors have no conflict of interest to declare.

\section{FUNDING SOURCE}

The inks used in the study are self-funded by the authors.

\section{REFERENCES}

1. Tampi C. In search of the rainbow: Colored inks in surgical pathology. Indian J Pathol Microbiol. 2012;55:154-7.

2. Sarode SC, Sarode GS, Patil S, Mahajan P, Anand R, Patil A. Comparative Study of Acrylic Color and India Ink for their use as a surgical margin inks in oral squamous cell carcinoma. World J Dent. 2015;6:26-30.

3. Williams AS, Dakin Haché K. Variable fidelity of tissue-marking dyes in surgical pathology. Histopathology. 2014;64:896-900.

4. Westra WH, Hruban RH, Phelps TH, Isacson C. Surgical pathology dissection: An illustrated guide. $2^{\text {nd }}$ ed. New York: Springer; 2003. Chapter 1, General approach to surgical pathology specimens; p. 2-13.

5. Shinde V, Phelan C, Gater W, Thomas J. Inking a specimen without the mess. J Clin Pathol. 2008;61:783.

6. Williams AS, Hache KD. Recognition and discrimination of tissuemarking dye color by surgical pathologists recommendations to avoid errors in margin assessment. Am J Clin Pathol. 2014;142:355-61.

7. Chiam HW, Maslen PG, Hoffman GJ. Marking the surgical margins of specimens: Commercial acrylic pigments are reliable, rapid and safe. Pathology. 2003;35:204-6.

8. Wong JW, Bai H, Abdul-Karim FW, Maclennan GT. Simulation of microcalcifications on specimen radiographs of breast biopsies by inks used in marking the surgical resection margins. Breast Journal. 2004;10:423-6.

9. Paterson DA, Davies JD. Marking planes of surgical excision on breast biopsy specimens: Use of artists' pigments suspended in acetone. J Clin Pathol. 1988;41:1013-6.

10. Ranjan R, Singh L, Arava SK, Singh MK. Margins in skin excision biopsies: Principles and guidelines. Indian J Dermatol. 2014;59:567-70.

11. Parkinson AB, Cannon CR, Hayne ST. Colour coding surgical margins with the Davidson marking system. J Histotechnol. 1990;13:293-4. 